Journal of Mathematics and Informatics

Vol. 15, 2019, 33-48

ISSN: 2349-0632 (P), 2349-0640 (online)

Published 31 January 2019

www.researchmathsci.org

DOI: http://dx.doi.org/10.22457/jmi.123av15a4

Journal of

Mathematics and

Informatics

\title{
Modeling Transmission Dynamics of Northern Corn Leaf Blight Disease with Seasonal Weather Variations
}

\author{
Fred Kapange ${ }^{I}$, Jacob Ismail Irunde ${ }^{2}$ and Dmitry Kuznetsov ${ }^{I}$ \\ ${ }^{1}$ Department of Mathematics \\ The Nelson Mandela African Institution of Science and Technology \\ P.O.Box 447, Arusha, Tanzania \\ ${ }^{2}$ Department of Mathematics, Mkwawa University College of Education \\ P.O.Box 2513, Iringa, Tanzania. email: jacobirunde@ gmail.com \\ Corresponding author. email: kapangefred018@gmail.com
}

Received 6 December 2018; accepted 20 January 2019

\begin{abstract}
Northern Corn Leaf Blight (NCLB) disease is a fungal foliar disease caused by Exserohilum turcicum. Moderate temperature and high relative humidity are climatical conditions which favor the development of NCLB disease. A deterministic model for transmission dynamics of NCLB disease with seasonal weather variations is developed and vigorously analyzed. The basic reproduction number $R_{0}$ in the absence and presence of the impact of temperature and relative humidity is computed and the sensitivity analysis performed to determine the parameters' relationship with basic reproduction number $R_{0}$. The analysis shows that transmission rate from pathogen to susceptible maize plants, the pathogen's shedding rate from infected maize plants to the environment and maize plants disease induced death rate are more sensitive to NCLB disease dynamics and they play an important role in its transmission. On the other hands when there are high or low temperature and low humidity, sensitive negative parameters increases as the results NCLB disease development decreases. However, increasing parameters such as natural death rate of the pathogen, the natural death rate for maize plants and maize plants' disease induced death rate which have negative indices will reduce new infections. Moderate temperature and high relative humidity influence NCLB disease development.
\end{abstract}

Keywords: Northern Corn Leaf Blight, Exserohilum Turcicum, Seasonal, Weather Variations.

AMS Mathematics Subject Classification (2010): 00A71, 00A72, 92D30, 49Q12

\section{Introduction}

Northern Corn Leaf Blight (NCLB) disease is a fungus infection caused by a pathogen known as Exserohilum turcicum (ET). This fungus is favored by moderate temperature, high relative humidity and rainfall $[14,18,20]$. The NCLB disease has become a serious problem in agricultural production, especially in developing countries compared to developed countries [6]. It has now spread to African countries such as Tanzania, Zambia, South Africa, Kenya, Uganda, and Ethiopia [15]. 
Fred Kapange, Jacob Ismail Irunde and Dmitry Kuznetsov

In Tanzania, the NCLB disease has been reported in regions with high relative humidity, moderate temperature, and high rainfall [15]. The regions which are most affected are Mbeya and Arusha compared to coastal regions which have a high temperature, lowhumidity, and low rainfall [14]. Initially, the disease occurs during the winter period, when E.turcicum produced spores on maize residue especially when there are favorable conditions such as moderate temperature, relative humidity and heavy rainfall $[15,18]$. When the temperature rises the Turcicum produces spores on the surface of maize residue. The spores are then dispersed by the wind, rain splash and birds to spread the pathogens to the lower leaves of a new maize crop and affect them. For infection to occur it requires the temperature between 17.8 to $28 \mathrm{C}^{0}$ and moisture on maize leaf for 6 to 18 hours [18]. The infection on the maize leaf surface takes up to two weeks to occur [18, 20]. At the end of the season after harvesting, the pathogen remain on the infected maize residue, waiting for the next season $[18,20]$.

The symptoms of NCLB disease include; eyespot on the leaves, grayish green in color with water-soaked lesions and cigar-shaped $[18,20]$. The spots turn greenish with age and increase in size and finally attaining a spindle shape [18]. NCLB disease develops early in the season and during pollination stage for a long period affects a large area of the leaf responsible for manufacturing plant food [21]. The photosynthetic area of the leaf is affected reducing the efficiency of photosynthesis and hence reducing grain fill and yield [21]. The NCLB disease leads to an average yield loss of maize of $60 \%$ as reported in Kenya, Uganda, Ethiopia, South Africa and Zambia [14].

NCLB disease still remains a problem which lowers maize production yield, especially in areas, with favorable conditions such as heavy rainfall, high relative humidity, and moderate temperature [3]. Bucheyeki [3] used an experimental approach to explain how farmers could use maize seeds which are resistant to NCLB disease. However, the study explains less the interaction of maize and pathogen in the presence of climatic conditions which favor NCLB disease. Pechanova and Pechan [16] addressed NCLB by considering resistant pathogen and susceptible maize but less consider climatic conditions. Abebe and Singburaudom [1] used a statistical approach to survey and collect data on an isolated fungus which cause NCLB disease. However, less considered seasonal weather variations. This study uses a mathematical model to describe the transmission dynamics of NCLB disease with the impact of seasonal weather variations.

\section{Materials and methods}

\subsection{Model development}

The model is formulated by modifying the SEIR model which was developed by Van Driesch and Watmough [19]. The proposed model consists of two populations which are maize plants and fungus. The population of maize plants are divided into two classes which are the susceptible class, $S_{m}$ and infected maize, $I_{m}$. Fungus population which causes NCLB disease is represented by $P_{0}$. Susceptible maize plants are recruited by planting at a rate of $\gamma$ and decrease when they suffer natural mortality and acquire NCLB disease at rates $\mu_{m}$ and $\theta_{P m(T)}$ respectively. Infected maize increase when susceptible

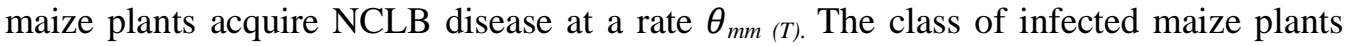
decreases due to induced and natural mortalities at rates $\delta_{m(T)}$ and $\mu_{m}$ respectively. The fungus which causes NCLB disease are referred to as pathogens and they are recruited at a rate $\alpha(T, H)$. However, they suffer natural mortality at a rate of $\mu_{0}$. Parameters $K_{l}$ and 
Modeling Transmission Dynamics of Northern Corn Leaf Blight Disease with Seasonal Weather Variations

$K_{2}$ are maize plants' and the pathogen's carrying capacities respectively. The state variables are described in Table 1 and parameters are described in Table 2.

Table 1: Variable and their descriptions

\begin{tabular}{cll}
\hline Variables & Description & Units \\
\hline$N_{m}$ & Total number of maize plants & Plant ha $^{-1}$ \\
$S_{m}$ & Susceptible maize plants & Plant ha $^{-1}$ \\
$I_{m}$ & Infected maize plants & Plant ha $^{-1}$ \\
$P_{0}$ & Pathogens'population in the environmentresidual & Cells ha $^{-1}$ \\
\hline
\end{tabular}

Table 2: Parameters and their description

\begin{tabular}{|c|c|c|}
\hline Parameters & Description & $\begin{array}{l}\text { Dependent on climatic } \\
\text { change }\end{array}$ \\
\hline$\mu_{0}$ & Pathogen's natural death rate & Not considered \\
\hline$\mu_{m}$ & Maize natural death rate & Not considered \\
\hline$\delta_{m(T)}$ & $\begin{array}{l}\text { Maize plants' disease induced death } \\
\text { rate }\end{array}$ & Temperature \\
\hline$\alpha(T, H)$ & Recruitment rate of pathogen & Temperature and Humidity \\
\hline$\theta_{\mathrm{pm}(\mathrm{T})}$ & $\begin{array}{l}\text { NCLB transmission rate from } \\
\text { pathogen to susceptible maize } \\
\text { plants. }\end{array}$ & Temperature \\
\hline$\theta_{\mathrm{mm}(\mathrm{T})}$ & $\begin{array}{l}\text { NCLB transmission rate from } \\
\text { infected maize plants to susceptible } \\
\text { maize plants. }\end{array}$ & Temperature \\
\hline$\theta_{m p(T)}$ & $\begin{array}{l}\text { Pathogens' shedding rate from } \\
\text { infected maize plant to } \\
\text { environment. }\end{array}$ & Temperature \\
\hline$\beta_{m m}$ & $\begin{array}{l}\text { NCLB transmission rate infected } \\
\text { maize plants to susceptible maize } \\
\text { plants }\end{array}$ & Not considered \\
\hline$\beta_{p m}$ & $\begin{array}{l}\text { NCLB transmission rate from } \\
\text { pathogen to susceptible maize } \\
\text { plants }\end{array}$ & Not considered \\
\hline$\beta_{m p}$ & $\begin{array}{l}\text { Shelding rate from infected maize to } \\
\text { the pathogen environment }\end{array}$ & Not considered \\
\hline$\gamma$ & Recruitment rate for maize plants & Not considered \\
\hline$K_{1}$ & Maize plants carrying capacity & Not considered \\
\hline$K_{2}$ & Pathogen's carrying capacity & Not considered \\
\hline
\end{tabular}

\subsection{Assumptions of the model}


Fred Kapange, Jacob Ismail Irunde and Dmitry Kuznetsov

The model assumes that all newly planted maize are susceptible to NCLB disease. The recruitment rate for new maize plants is through planting. The transmission of infections from maize residue to susceptible maize plants is through wind, rain splash, and birds.

The infected maize plants shed pathogen to the environment through wind, rain splash, and birds.

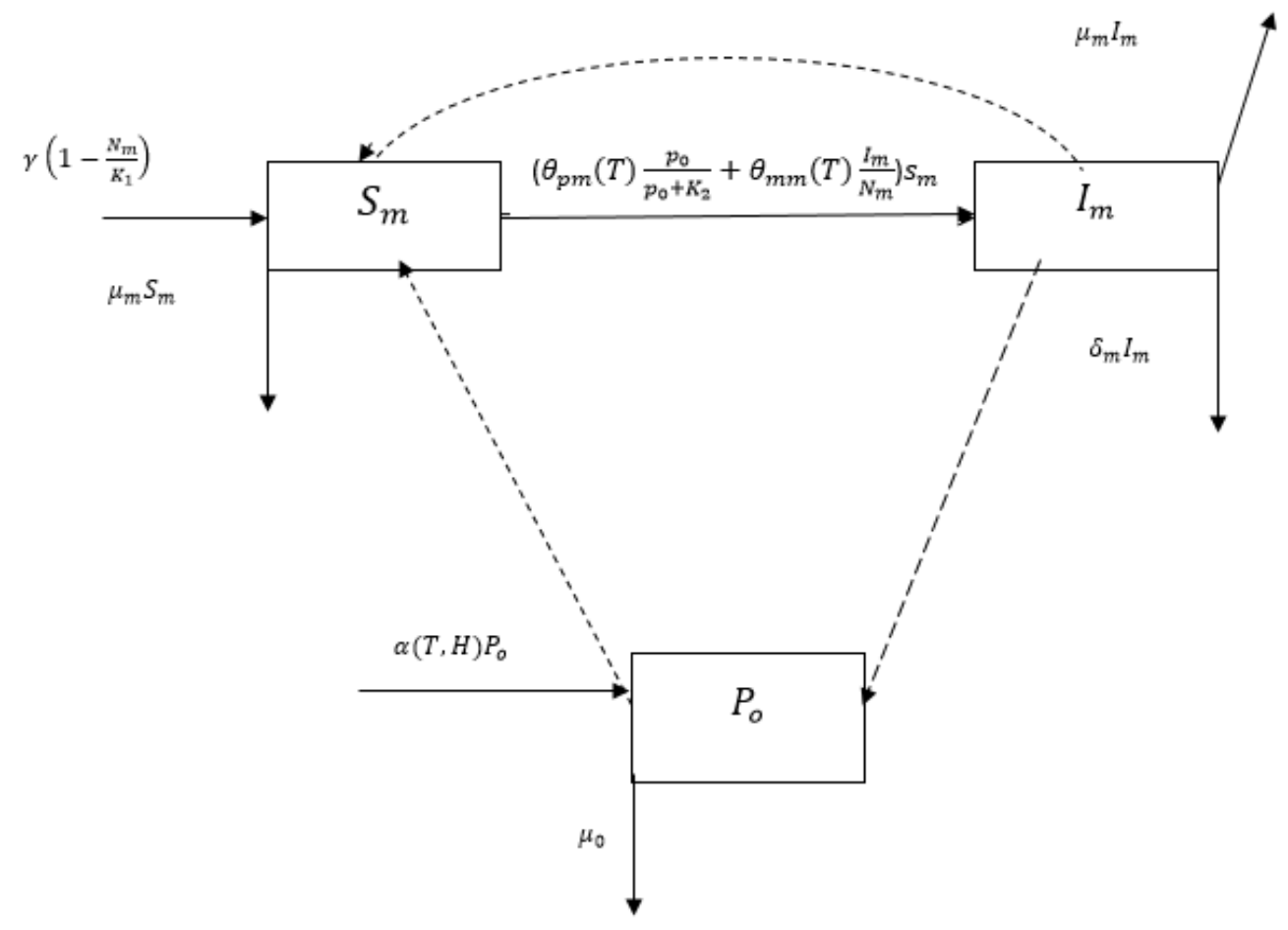

2.3.The model equations

Figure 1: Compartmental model

Putting formulations together, dynamics of NCLB disease is described by the following equations:

$$
\begin{gathered}
\frac{\boldsymbol{d} \boldsymbol{S}_{m}}{\boldsymbol{d} t}=\gamma\left(1-\frac{N_{m}}{K_{1}}\right)-\left(\theta_{p m}(T) \frac{\mathrm{P} o}{\mathrm{P} o+K_{2}}+\theta_{m m}(T) \frac{I_{m}}{N_{m}}\right) \mathrm{S}_{\mathrm{m}}-\mu_{m} S_{m}, \\
\frac{\boldsymbol{d} \boldsymbol{I}_{m}}{\boldsymbol{d} t}=\left(\theta_{p m}(T) \frac{\mathrm{P} o}{\mathrm{P} o+K_{2}}+\theta_{m m}(T) \frac{I_{m}}{N_{m}}\right) S_{m}-\delta \mathrm{m}(T) I_{m}-\mu_{m} I_{m}, \\
\frac{\boldsymbol{d \mathrm { P } _ { 0 }}}{\boldsymbol{d} \boldsymbol{t}}=\theta_{m p}(\mathrm{~T}) \frac{\boldsymbol{I}_{m}}{\boldsymbol{N}_{m}}+\alpha(\mathrm{T}, \mathrm{H}) P_{0}-\mu_{0} \mathrm{P}_{0} .
\end{gathered}
$$

Initial $\quad \mathrm{S}_{m}>0, I_{m} \geq 0, P_{0} \geq 0$.

\section{Model analysis}

\subsection{Basic properties of the model}

To determine if the model is mathematically and epidemiologically meaningful, two model properties are considered, which are invariant region and positivity of the solution.

\subsubsection{The invariant region}


Modeling Transmission Dynamics of Northern Corn Leaf Blight Disease with Seasonal Weather Variations

The NCLB disease model (1) has two population and three classes, we assumed that all state variables and parameters from the model system are positive $\forall t \geq 0$

Theorem 1. Given the model system (1) in $R_{+}^{3}$ with the initial conditions; where $S_{m(0)}>0, I_{m(0)} \geq 0, P_{0(0)} \geq 0$. Its solution enter the invariant region; $\phi=\phi_{1}+\phi_{2}$, where

$\phi_{2}=\left\{P_{0}(T) \in R_{+}^{1}\right\}$

$$
\phi_{1}=\left\{S_{m}(T), I_{m}(T) \in R_{+}^{2}\right\},
$$

Proof:To establish the invariant region for NCLB disease model system (1), box invariant method is applied $[4,8,9,11,13,22]$. Using this method, the system (1) is written as:

where;

$$
\frac{d X}{d t}=Z(x) X+F
$$

$X=\left(S_{m}, I_{m}, P_{o}\right)^{\mathrm{T}}$ and $F=\left(\gamma\left(1-\frac{N_{m}}{\mu_{m} K_{1}}\right), 0,0\right)^{\mathrm{T}} \geq 0, \mathrm{~F}$ is a column vector and $\mathrm{Z}(\mathrm{x})$ is a $3 \times 3$ matrix such that:

$$
Z(x)=\left[\begin{array}{cccc}
Z_{1}(x) & 0 & 0 & 0 \\
0 & 0 & 0 & Z_{2(x)}
\end{array}\right] .
$$

The sub-matrix $\boldsymbol{Z}_{\mathbf{1}}(\boldsymbol{x})$ and $\boldsymbol{Z}_{\mathbf{2}(x)}$ form a metzler matrix $Z$ (x) for model (1). Sub-matrix $\boldsymbol{Z}_{\mathbf{1}}(\boldsymbol{x})$ represents maize plant population and sub-matrix $\boldsymbol{Z}_{\mathbf{2}(\boldsymbol{x})}$ represents pathogen in the environment and they are defined as follows;

$$
\begin{aligned}
& Z_{1}(x)=\left[\begin{array}{ccc}
-D_{m}-\mu_{m} & 0 & 0 \\
D_{m} & -\delta_{m(T)}-\mu_{m} & 0
\end{array}\right], \\
& Z_{2}(x)=\left[\begin{array}{lll}
0 & \frac{\theta_{m p}(T)}{N_{m}} & -\left(\mu_{0-\alpha(T, H)}\right)
\end{array}\right],(6)
\end{aligned}
$$

Combination of sub-matrices $\boldsymbol{Z}_{\mathbf{1}}(\boldsymbol{x})$ and $\boldsymbol{Z}_{\mathbf{2}(\boldsymbol{x})}$ forms the matrix $\mathrm{Z}(\mathrm{x})$ which is written as:

$$
Z(x)=\left[\begin{array}{ccc}
-D_{m}-\mu_{m} & 0 & 0 \\
D_{m} & -\delta_{m(T)}-\mu_{m} & 0 \\
0 & \frac{\theta_{m p}(T)}{N_{m}} & -\left(\mu_{0-\alpha(T, H)}\right)
\end{array}\right] .
$$

A metzler matrix $\mathrm{Z}(\mathrm{x})$ in (7) has negative elements in the main diagonal and non-negative off diagonal elements if and only if $\alpha(T, H)<\mu_{0}$. Hence this shows that, solutions of model (1) enter the invariant region:

$$
\phi=\left\{S_{m}(T), I_{m}(T) \in R_{+}^{2} ; P_{0}(T) \in R_{+}^{1}\right\} .
$$

\subsubsection{Positivity of the solution}

Theorem 2. Let initial value for the model system (1) be $S_{m}(0)>0, I_{m}(0) \geq 0$ and $P_{0}(0) \geq 0$. The solution set $S_{m}(\mathrm{t}), I_{m}(\mathrm{t})$ and $P_{0}(\mathrm{t})$ are non-negative, $\forall \mathrm{t} \geq 0$.

Proof: From the first equation of the model (1).

$$
\begin{aligned}
& \frac{\mathrm{d} S_{\mathrm{m}}(\mathrm{t})}{\mathrm{dt}}=\gamma\left(1-\frac{N_{m}}{K_{1}}\right)-\left(\theta_{p m}(T) \frac{\mathrm{Po}}{\mathrm{P} o+K_{2}}+\theta_{m m}(T) \frac{I_{m}}{N_{m}}\right) \mathrm{S}_{\mathrm{m}}(t)-\mu_{m} S_{m}, \\
& \frac{d S_{m}(t)}{d t}>-\left(\theta_{p m}(T) \frac{\mathrm{P} o}{\mathrm{P} o+K_{2}}+\theta_{m m}(T) \frac{I_{m}}{N_{m}}\right) \mathrm{S}_{\mathrm{m}}(t)-\mu_{m} S_{m}(t),
\end{aligned}
$$


Fred Kapange, Jacob Ismail Irunde and Dmitry Kuznetsov

$$
\int_{\mathbf{0}}^{t} \frac{\boldsymbol{t} \boldsymbol{S}_{\boldsymbol{m}}(\boldsymbol{t})}{\boldsymbol{S}_{\boldsymbol{m}}(\boldsymbol{t})}>-\int_{\mathbf{0}}^{\boldsymbol{t}}\left(\theta_{p m}(T) \frac{\mathrm{Po}}{\mathrm{P} o+K_{2}}+\theta_{m m}(T) \frac{I_{m}}{N_{m}}+\mu_{m}\right) \mathrm{dt} .
$$

Integrating both side;

$$
\begin{gathered}
\int_{\mathbf{0}}^{\boldsymbol{t}} \frac{\boldsymbol{d} \boldsymbol{S}_{\boldsymbol{m}}(\boldsymbol{t})}{\boldsymbol{S}_{\boldsymbol{m}}(\boldsymbol{t})}>-\int_{\mathbf{0}}^{\boldsymbol{t}}\left(\theta_{p m}(T) \frac{\mathrm{P} o}{\mathrm{P} o+K_{2}}+\theta_{m m}(T) \frac{I_{m}}{N_{m}}+\mu_{m}\right) \boldsymbol{d} \boldsymbol{s}, \\
\ln \left(\mathrm{S}_{\mathrm{m})>-}\left(\theta_{p m}(T) \frac{\mathrm{Po}}{\mathrm{P} o+K_{2}}+\theta_{m m}(T) \frac{I_{m}}{N_{m}}+\mu_{m}\right) \boldsymbol{d} \boldsymbol{s},\right. \\
\mathrm{S}_{\mathrm{m}}(0) \geq \mathrm{S}_{\mathrm{m}}(0) \mathrm{e}^{-\int_{\mathbf{0}}^{t}\left(\theta_{p m}(T) \frac{\mathrm{Po}}{\mathrm{P} o+K_{2}}+\theta_{m m}(T) \frac{I_{m}}{N_{m}}+\mu_{m}\right) \boldsymbol{d} \boldsymbol{s}}>0 .
\end{gathered}
$$

From second equation of the model (1b);

$$
\frac{\boldsymbol{d} \boldsymbol{I}_{\boldsymbol{m}}(\boldsymbol{t})}{\boldsymbol{d} \boldsymbol{t}}=\left(\theta_{p m}(T) \frac{\mathrm{P} o}{\mathrm{P} o+\mathrm{K}}+\theta_{m m}(T) \frac{I_{m}}{N_{m}}\right) S_{m-} \delta \mathrm{m}(T) I_{m}(t)-\mu_{m} I_{m}(t) .
$$

Integrating both sides gives:

$I_{m}(0) \geq I_{m}(0) \mathrm{e}^{-\left(\delta \mathrm{m}(T)+\mu_{m}\right) \mathrm{t}}$,

Hence; $I_{m}(0) \geq 0, \forall t \geq 0$.

Through the same procedure we have, $P_{O} \geq 0, \forall \mathrm{t} \geq 0$. This shows that all solutions are positive for all $t>0$.

\subsection{Existence of the disease free equilibrium}

The point when there is no disease is referred to disease free equilibrium [4]. We obtain disease free equilibrium when the infected classes are zero. When infected classes are zero disease free equilibrium is given by:

$$
\left(S_{m}, I_{m}, P_{0}\right)=\left(\gamma\left(1-\frac{N_{m}}{\mu_{m} K_{1}}\right), 0,0\right) .
$$

At disease-free equilibrium, there is no disease, hence all maize plants are susceptible to NCLB.

\subsection{The basic reproduction number $\boldsymbol{R}_{0}$}

The basic reproduction number $R o$ measures the average new infections when pathogen attack susceptible maize plants [4]. As we consider seasonality, the number of secondary infections at a particular time when pathogens are introduced will depend on seasonality

[7]. The basic reproduction number $R_{0}$ is computed by using the next-generation matrix operator [11] as follows:

Let the next generation matrix be $A$, with elements $A_{\mathrm{ijs}}$. Each element $A_{i j}$ explains the expected number of new cases of type $i$ which is caused by a pathogen of typej. By defining the next-generation matrix $A$ whose entries are $A \mathrm{ij}$, the basic reproduction number $R o$ is given by:

$$
R_{0}=\rho(A)
$$

The next-generation matrix is given by:

$$
A=\left[\begin{array}{ll}
A_{11} & A_{12} \\
A_{21} & A_{22}
\end{array}\right]
$$


Modeling Transmission Dynamics of Northern Corn Leaf Blight Disease with Seasonal Weather Variations

$A_{11}$ is the expected number of NCLB new cases in susceptible maize plants which are caused by infected maize plants, $A_{12}$ is expected number of NCLB new cases in susceptible maize plants which are caused by pathogens from environment, $A_{21}$ is expected number of new cases in pathogens in the environment which are caused by pathogens from infected maize plants through shedding. Since it is assumed that fungus has no vertical transmission, $A_{22}=0$ and hence:

$$
A=\left[\begin{array}{cc}
A_{11} & A_{12} \\
A_{21} & 0
\end{array}\right]
$$

The expression of each element in matrix A is expressed as a product of effective contact rate and duration of infection [13]. Thus:

$$
\begin{aligned}
& A_{11}=\theta_{m m(T)} X \frac{1}{\delta_{m}(T)+\mu_{m}}, \\
& A_{12}=\theta_{p m(T)} X \frac{1}{\mu_{o}}, \\
& A_{21}=\theta_{m p(T)} X \frac{1}{\delta_{m}(T)+\mu_{m}} .
\end{aligned}
$$

From matrix $A$, the basic reproduction number $R_{0}$ is given by:

$$
R_{O}=\frac{\theta_{m m}(T) \mu_{o}+\sqrt{\theta_{m m}^{2}(T) \mu_{o}^{2}+4 \delta_{m}(T) \theta_{p m}(T) \theta_{m p}(T) \mu_{o}+4 \theta_{p m}(T) \theta_{m p}(T) \mu_{o} \mu_{m}}}{2\left(\delta_{m}(T)+\mu_{m}\right) \mu_{o}} .
$$

The basic reproduction number $R_{O}$ depends on NCLB transmission rate from pathogen to susceptible maize plants, shedding rate from infected maize to the pathogen environment and NCLB transmission rate from infected maize plants to susceptible maize plants which are proportional to the basic reproduction number $R_{O}$. The natural death rate for maize plants, maize plants NCLB induced mortality death rate and natural death rate for pathogen are inversely proportional to basic reproduction number $R_{O}$.

\subsection{Sensitivity analysis}

Sensitivity analysis helps to determine which parameters are sensitive to the transmission dynamics of the disease $[2,4,12]$. To obtain the parameter's forward sensitivity index, we differentiate the basic reproduction number $R_{O}$ with respect to that parameter. If $w$ is the parameters in the basic reproduction number $R_{O}$, then the normalized forward sensitivity index of $w$ with respect to $R_{O}$ is given by:

$$
r_{w}^{R_{o}}=\frac{\partial\left(R_{o}\right)}{\partial(w)} \times \frac{w}{R_{o}}
$$

\subsection{Parameters estimation}

This study uses parameter values from related literature and estimated parameter values from sensitivity analysis. Germination and effective contact rates were fitted from seasonal weather variations data from the Tanzania Meteorological Agency (TMA) from January to December, 2017. Tables 3, 4 and 5 show the parameter values which are used for simulations and their corresponding sources. 
Fred Kapange, Jacob Ismail Irunde and Dmitry Kuznetsov

\subsubsection{The Germination rate of pathogen}

Exserohilum turcicum germinates spores on maize residue especially when humidity and temperature are favorable [15]. To calculate the life span of infected maize plants, the formula which is used to calculate the life span of mosquitoes is adopted because the sexual stage of the fungus Exserohilum turcicum rarely occurs [11]. The Life span of infected maize plant is given by:

$$
\frac{1}{\delta_{m}(T)}=C_{O}-C_{1}(T) \text {. }
$$

where $C_{0}$ is a slope and $C_{1}$ is the intercept.

Using monthly temperature data from Arusha and Mbeya regions in 2017 and the equation for life span of infected maize plant (18), the slope, the intercept and the minimum temperature for each region are $C_{0}=2.30475, C_{1}=0.18804, T_{\min }=15 C^{0}$ and $C_{0}=2.371264, C_{1}=0.192959, T_{\min }=15 C^{0}$ respectively. To compute the growth rate for fungus, we modify the formula which is used to compute the growth rate of Fusarium graminearum as applied by Manstretta and Rossi [10,17]. The fungus growth rate is given by:

$$
\begin{aligned}
& \alpha(T)=a_{1}\left[\frac{T-T_{\min }}{T_{\max }-T_{\min }}\right]^{a_{2}} *\left[1-\left(\frac{T-T_{\min }}{T_{\max }-T_{\min }}\right)\right]^{a_{3}} \\
& \alpha(H)=a_{3}{ }^{(100-R H)} /\left(1+e^{a_{1}}\right)
\end{aligned}
$$

where $T$ is the optimum temperature, $T_{\max }$ and $T_{\min }$ are the maximum and minimum temperature $\left(C^{o}\right), a_{1}, a_{2}$ and $a_{3}$ are the control parameters of growth equation for fungus and $R H$ is relative humidity (\%) [10]. The control parameters $a_{1}, a_{2}, a_{3}$ and maximum temperature $\left(T_{\max }\right)$ are assumed to be:

$$
\begin{gathered}
a_{1}=0.0135, \\
a_{2}=0.198, \\
a_{3}=0.750, \\
T_{\max }=30 C^{0}, \\
T_{\min }<T<T_{\max } .
\end{gathered}
$$

\subsubsection{Adequate contact rate}

Each element $A_{i j}$ in matrix $A$, represents the expected number of new cases of the $i^{t h}$ type caused by pathogen of $j^{t h}$ type. $A_{i j}$ is the product of effective transmission rate and duration of infection. The probability of NCLB transmission is assumed to depend on temperature [11].

$$
\begin{aligned}
& B(T)=a_{\text {slope }}\left(T-T_{\text {min }}\right) \\
& \left.\theta_{p m(T)}=a_{\text {slope }\left(T-T_{\min }\right.}\right) \beta_{p m}, \beta_{p m}=0.088 \\
& \left.\theta_{m m(T)}=a_{\text {slope }\left(T-T_{\min }\right)}\right) \beta_{m m}, \beta_{m m}=0.2868 \\
& \left.\theta_{m p(T)}=a_{\text {slope }\left(T-T_{\min }\right.}\right) \beta_{m p}, \beta_{m p}=0.01
\end{aligned}
$$

Climatic data from Arusha and Mbeya regions in Tanzania are used to study the effect of seasonal weather variations on basic reproduction number $R_{0}$ from January to December, 2017. These data were collected from the Tanzania Meteorological Agency 
Modeling Transmission Dynamics of Northern Corn Leaf Blight Disease with Seasonal Weather Variations

(TMA) in 2017. Parameter values are summarized in Tables 3, 4 and 5. Table 3 summarizes parameter values when temperature and relative humidity are not considered.

Table 3:Parameters with estimated values of the model (1) without considering the impact of temperature and relative humidity.

\begin{tabular}{cll}
\hline Parameters & Parameter Value & Source \\
\hline$\mu_{0}$ & 0.001 day $^{-1}$ & Assumed \\
$\mu_{m}$ & 0.0002 day $^{-1}$ & Assumed \\
$\delta_{m}$ & 0.04 day $^{-1}$ & Assumed \\
$\alpha$ & 0.011 day $^{-1}$ & Assumed \\
$\beta_{p m}$ & $0.088 d a y^{-1}$ & Assumed \\
$\beta_{m p}$ & 0.01 day $^{-1}$ & Assumed \\
$\beta_{m m}$ & 0.2868 day $^{-1}$ & Assumed \\
$\gamma$ & $276.8212 \mathrm{day}^{-1}$ & {$[5]$} \\
$N_{m}$ & $44000{\text { plant } h a^{-1}}^{-1}$ & {$[2]$} \\
$K_{1}$ & $60000{\text { plant } h a^{-1}}^{2}$ & Assumed \\
$K_{2}$ & $50 M^{-3}$ & {$[2]$} \\
\hline
\end{tabular}

In Tables 4 and 5 numerical value for basic reproduction number is computed using data from Arusha and Mbeya regions. The highest values for basic reproduction number $R_{0}$ in Mbeya is 1.4383 and 1.3949 in Arusha.

The lowest values for basic reproduction number $R_{0}$ in Mbeya and Arusha are 0.5477 and 0.9568 respectively. The case study for two regions shows that Mbeya is more affected by NCLB disease than Arusha.

Table 4: Parameter values of the model (1) with low and high $R_{0}$ in presence of climatical data in Arusha

\begin{tabular}{clll}
\hline Parameters & $\begin{array}{l}\text { High Parameter } \\
\text { Value }\end{array}$ & Low Parameter Value & Source \\
& 0.001 day $^{-1}$ & 0.001 day $^{-1}$ & \\
\hline$\mu_{0}$ & 0.0002 day $^{-1}$ & 0.0002 day $^{-1}$ & Assumed \\
$\mu_{m}$ & 0.64435 day $^{-1}$ & 1.311 day $^{-1}$ & Assumed \\
$\delta_{m(T)}$ & 0.0125 day $^{-1}$ & 0.0205 day $^{-1}$ & Fitted \\
$\alpha(T, H)$ & 0.0662 day $^{-1}$ & 0.135689 day $^{-1}$ & Fitted \\
$\theta_{\mathrm{pm}(\mathrm{T})}$ & & & Fitted
\end{tabular}


Fred Kapange, Jacob Ismail Irunde and Dmitry Kuznetsov

\begin{tabular}{clll}
$\theta_{\mathrm{mp}(\mathrm{T})}$ & 0.007526 day $^{-1}$ & 0.015419 day $^{-1}$ & Fitted \\
$\theta_{\mathrm{mm}(\mathrm{T})}$ & 0.21586 day $^{-1}$ & 0.4422 day $^{-1}$ & Fitted \\
$\beta_{p m}$ & 0.088 day $^{-1}$ & 0.088 day $^{-1}$ & Assumed \\
$\beta_{m p}$ & 0.01 day $^{-1}$ & 0.01 day $^{-1}$ & Assumed \\
$\beta_{\mathrm{mm}}$ & 0.2868 day $^{-1}$ & 0.2868 day $^{-1}$ & Assumed \\
$\delta_{m}$ & 0.04 day $^{-1}$ & 0.04 day $^{-1}$ & Assumed \\
$\gamma$ & 276.8212 day $^{-1}$ & 276.8212 day $^{-1}$ & {$[5]$} \\
$N_{m}$ & 44000 plantha $^{-1}$ & 44000 plantha $^{-1}$ & {$[2]$} \\
$K_{1}$ & 60000 plantha $^{-1}$ & 60000 plantha $^{-1}$ & Assumed \\
$K_{2}$ & $50 M^{-3}$ & $50 M^{-3}$ & {$[2]$} \\
\hline
\end{tabular}

Table 5: Parameter values of the model (1) with low and high $R_{0}$ in presence of climatical data in Mbeya

\begin{tabular}{clll}
\hline Parameters & High Parameter & Low Parameter Value & Source \\
& Value & & \\
\hline$\mu_{0}$ & 0.001 day $^{-1}$ & 0.001 day $^{-1}$ & Assumed \\
$\mu_{m}$ & 0.0002 day $^{-1}$ & 0.0002 day $^{-1}$ & Assumed \\
$\delta_{m(T)}$ & 0.5037 day $^{-1}$ & 1.267 day $^{-1}$ & Fitted \\
$\alpha(T, H)$ & 0.0071 day $^{-1}$ & 0.028 day $^{-1}$ & Fitted \\
$\theta_{\mathrm{pm}(\mathrm{T})}$ & 0.03398 day $^{-1}$ & 0.13924 day $^{-1}$ & Fitted \\
$\theta_{\mathrm{mp}(\mathrm{T})}$ & 0.00386 day $^{-1}$ & 0.01582 day $^{-1}$ & Fitted \\
$\theta_{\mathrm{mm}(\mathrm{T})}$ & 0.1107 day $^{-1}$ & 0.45379 day $^{-1}$ & Fitted \\
$\beta_{p m}$ & 0.088 day $^{-1}$ & 0.088 day $^{-1}$ & Assumed \\
$\beta_{m p}$ & 0.01 day $^{-1}$ & 0.01 day $^{-1}$ & Assumed \\
$\beta_{\mathrm{mm}}$ & 0.2868 day $^{-1}$ & 0.2868 day $^{-1}$ & Assumed \\
$\delta_{m}$ & 0.04 day $^{-1}$ & 0.04 day $^{-1}$ & Assumed \\
$\gamma$ & 276.8212 day $^{-1}$ & 276.8212 day $^{-1}$ & {$[5]$} \\
$N_{m}$ & 44000 plantha $^{-1}$ & 44000 plantha $^{-1}$ & {$[2]$} \\
$K_{1}$ & 60000 plantha $^{-1}$ & 60000 plantha $^{-1}$ & Assumed \\
$K_{2}$ & $50 M^{-3}$ & $50 M^{-3}$ & {$[2]$} \\
\hline
\end{tabular}

Tables 6,7 and 8 show clearly the most sensitive parameters to the basic reproduction number $R_{0}$. In Table 6 , the most sensitive parameters to the basic reproduction number $R_{0}$ are NCLB transmission rate from infected maize pants to susceptible maizeplants and disease-induced death rate in the maize plants. In Tables 7 and 8, the most sensitive parameters to the basic reproduction number $R_{0}$ are NCLB transmission rate from pathogen to susceptible maize plants, shedding rate from infected maize plant to the pathogen in the environment and disease-induced death rate in the maize plants. 
Modeling Transmission Dynamics of Northern Corn Leaf Blight Disease with Seasonal Weather Variations

Table 6: Sensitivity index without considering impact of climate change

\begin{tabular}{cl}
\hline Parameters & Sensitivity Index \\
\hline$\beta_{m m}$ & +0.6063028758 \\
$\beta_{p m}$ & +0.1968485620 \\
$\beta_{m p}$ & +0.1968485620 \\
$\mu_{0}$ & -0.1968485619 \\
$\delta_{m}$ & -0.7991556597 \\
$\mu_{m}$ & -0.003995778298 \\
\hline
\end{tabular}

Table 7: Sensitivity index with low and high parameter by considering impact of climate change in Arusha region

\begin{tabular}{cll}
\hline Parameters & $\begin{array}{l}\text { Low Parameter Sensitivity } \\
\text { Index }\end{array}$ & $\begin{array}{l}\text { High Parameter Sensitivity } \\
\text { Index }\end{array}$ \\
\hline$\theta_{m m(\mathrm{~T})}$ & +0.1870963397 & +0.1323178261 \\
$\theta_{p m(\mathrm{~T})}$ & +0.4064518298 & +0.4338410868 \\
$\theta_{m p(\mathrm{~T})}$ & +0.4064518298 & +0.4338410868 \\
$\mu_{0}$ & -0.40645182962 & -0.4338410866 \\
$\delta_{m}(T)$ & -0.5933639949 & -0.5660725556 \\
$\mu_{m}$ & -0.0001841744379 & -0.00008635736926 \\
\hline
\end{tabular}

Table 8: Sensitivity index with low and high parameter by considering impact of climate change in Mbeya region

\begin{tabular}{cll}
\hline Parameters & $\begin{array}{l}\text { Low Parameter Sensitivity } \\
\text { Index }\end{array}$ & $\begin{array}{l}\text { High Parameter Sensitivity } \\
\text { Index }\end{array}$ \\
\hline$\theta_{m m(\mathrm{~T})}$ & +0.2104752056 & +0.1345701415 \\
$\theta_{p m(\mathrm{~T})}$ & +0.3947623974 & +0.4327149290 \\
$\theta_{m p(\mathrm{~T})}$ & +0.3947623974 & +0.4327149290 \\
$\mu_{0}$ & -0.3947623974 & -0.4327149292 \\
$\delta_{m}(T)$ & -0.6049973813 & -0.5671955371 \\
$\mu_{m}$ & -0.0002402213148 & -0.00008953362859 \\
\hline
\end{tabular}


Fred Kapange, Jacob Ismail Irunde and Dmitry Kuznetsov

\section{Numerical simulation and discussion}

In this section, we simulate the basic reproduction number $R_{0}$ in presence of temperature and relative humidity. Figure 2, shows the variation of basic reproduction number $R_{0}$ using data from Arusha and Mbeya from January to December, 2017. According to the data, Mbeya is the most affected region by NCLB disease from January to March and from August to November. Arusha region suffers NCLB disease from January to March and from August, September, November, and December

Also in Figure 2 shows how NCLB disease varies with basic reproduction number $R_{0}$ with time in Mbeya and Arusha regions.

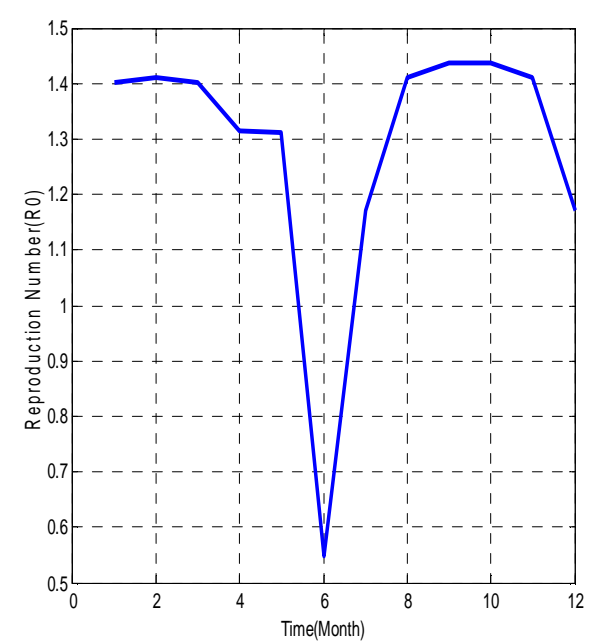

(A) Variation of $R_{0}$ with climatic data In Mbeya

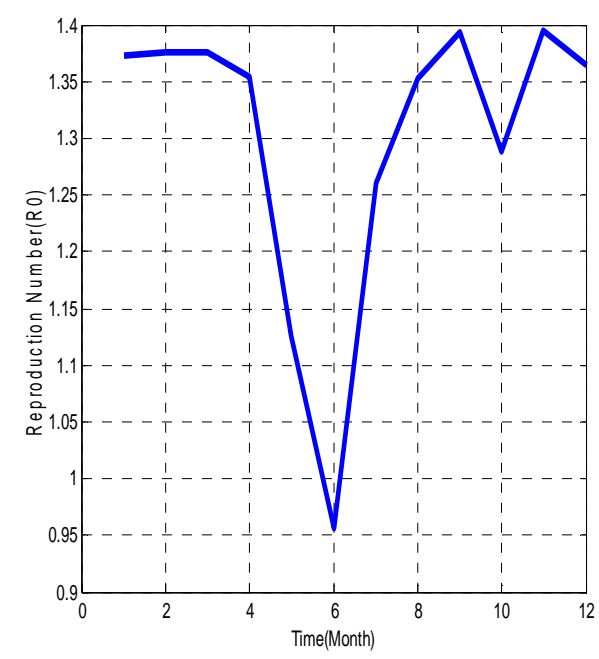

(B) Variation of $R_{0}$ with climate data in Arusha

Figure 2: Variation of basic reproduction number $R_{0}$ with climatic data in Mbeya and Arusha

The number of susceptible maize plants decreases when basic reproduction number $R_{0}$ increases as shown in Figures 3, at this time infected maize and pathogen increase.

Figure 4, shows a variation of basic reproduction number $R_{0}$ and temperature with time in Mbeya and Arusha regions from January to December, 2017. It is found that in the Arusha region NCLB average infection increase from January to March and from August, September, November, and December due to favorable temperature. However, they decrease in June and October due to unfavorable temperature to pathogens. In Mbeya region, $R_{0}$ increases from January to March and from August to November due to favorable temperature to pathogens and decreases in June and December, due to less favorable temperature to pathogens. 
Modeling Transmission Dynamics of Northern Corn Leaf Blight Disease with Seasonal Weather Variations

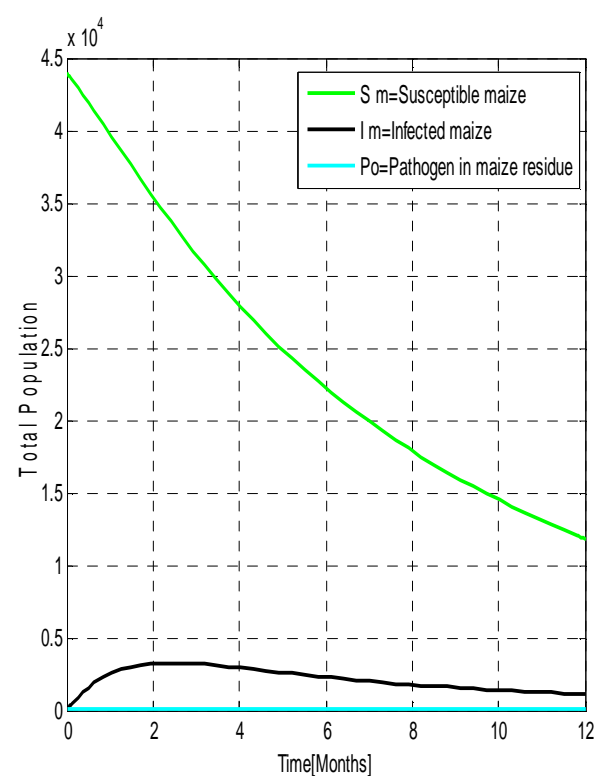

(A) NCLB model of general population In Arusha

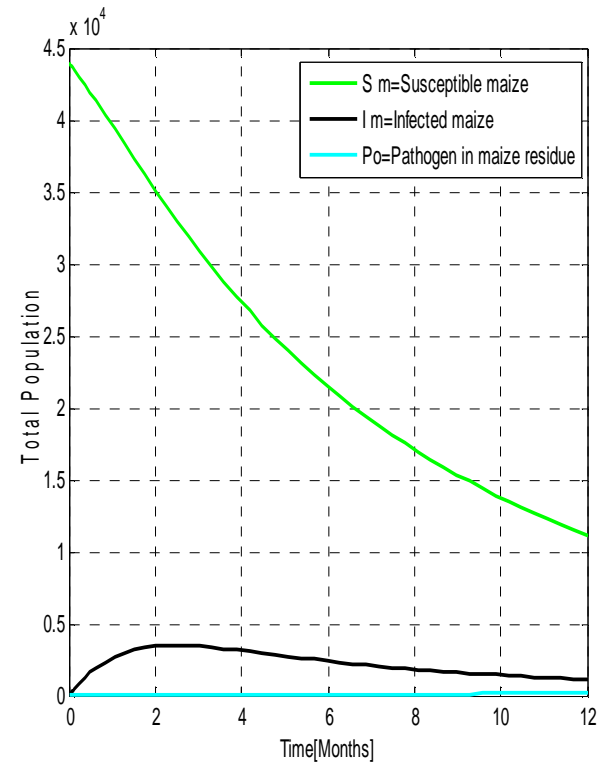

(B) NCLB model of general population in Mbeya

Figure 3: NCLB model with high impact of climate change in Arusha and Mbeya

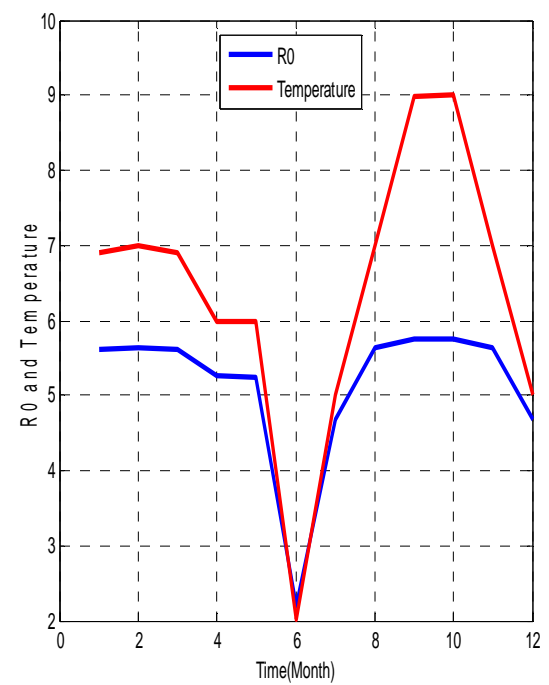

(A) Variation of $R_{0}$ and temperature with time in Mbeya.

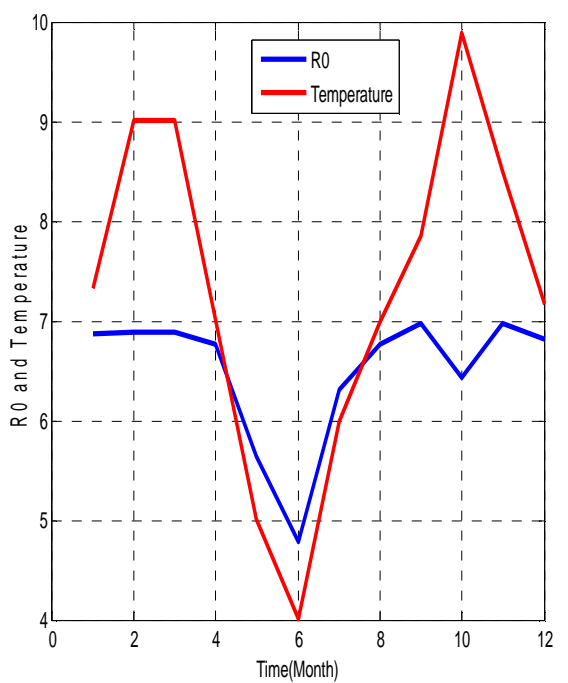

(B) Variation of $R_{0}$ and temperature with time in Arusha.

Figure 4: Variation of basic reproduction number $R_{0}$ and temperature with time in Arusha and Mbeya. 
Fred Kapange, Jacob Ismail Irunde and Dmitry Kuznetsov

The impact of temperature and relative humidity on the growth rate of the pathogen as shown in Figures 5 and 6. It is found that pathogen's growth rate and development of NCLB disease decreased in months which had high temperature and low relative humidity. When the temperature is moderate and relative humidity is high, pathogen's growth rate and development of NCLB disease increases. Climate change plays a great role in the development of pathogen which is responsible for NCLB disease.

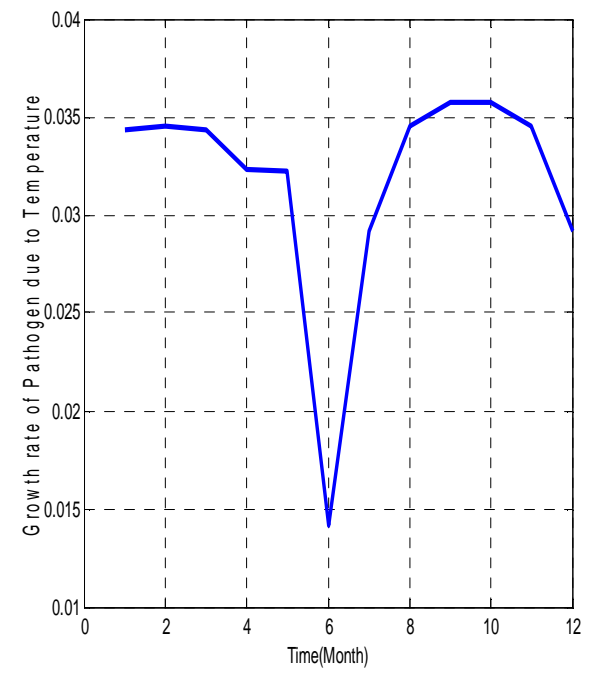

(A) Growth rate of pathogen due to impact of temperature in Mbeya

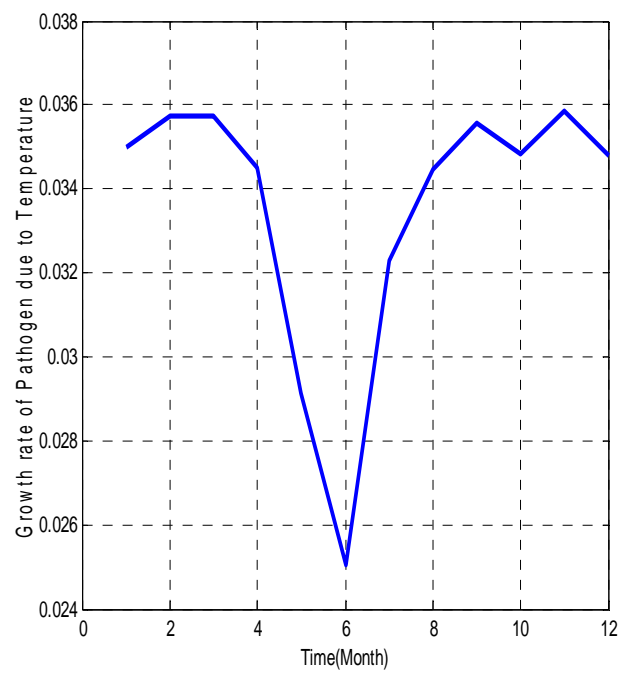

(B) Growth rate of pathogen due to impact of temperature in Arusha

Figure 5: Growth rate of pathogen due to impact of temperature in Mbeya and Arusha

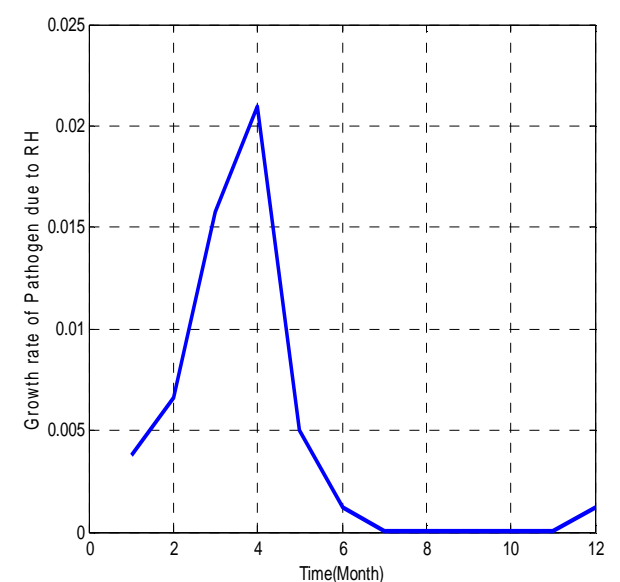

(A)Growth rate pathogen due to impact of $\mathrm{RH}$ in Mbeya

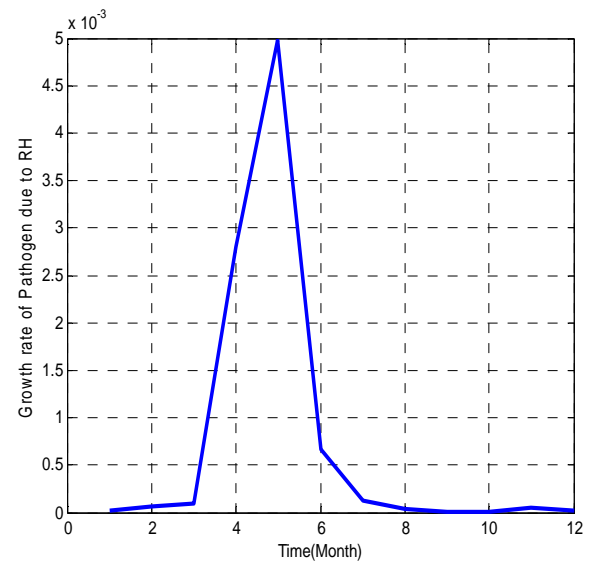

(B) Growth rate of pathogen due to impact of RH in Arusha

Figure 6: Growth rate of pathogen due to impact of RH in Mbeya and Arusha region. 
Modeling Transmission Dynamics of Northern Corn Leaf Blight Disease with Seasonal Weather Variations

\section{Conclusion}

A deterministic model of NCLB disease has been formulated to investigate the impact of climate change in two regions in Tanzania, Arusha and Mbeya regions from January to December, 2017. The basic reproduction number $R_{0}$ is computed and sensitivity index for each parameter in basic reproduction is derived. Using Matlab 2014a numerical simulations were performed by considering temperature and relative humidity to illustrate the dynamic behavior of NCLB disease in a closed population and show how parameters affect basic reproduction number $R_{0}$ and overall dynamics. Transmission rate from pathogen to susceptible maize plants, shedding rate of the pathogen from infected maize plants and plants' disease induced death rate is the most sensitive parameters to the NCLB disease. On other hands when there are high or low temperature and low humidity, sensitive negative parameters increases as the results NCLB disease development decreases. However increasing parameters such as natural death rate of the pathogen, the natural death rate for infected maize plants and maize plants' disease induced death rate will reduce new infections. Moderate temperature and high relative humidity will influence the development of NCLB disease. The study recommends that to improve food security where maize is a staple food, control strategies should focus on sensitive parameters that drive the disease transmission dynamics.

Acknowledgment. The author thanks NM-AIST management for the directives and support, Mbeya city council for granting a release of two years for studies and the supervisors for their support.

The authors are also grateful to the reviewers for their valuable suggestions to improve the presentation of the paper.

\section{REFERENCES}

1. D.Abebe and N.Singburaudom, Morphological, cultural and pathogenicity variation of Exserohilum turcicum (pass) Leonard and suggs isolates in maize (zea mays 1.). Kasetsart Journal (Nat. Sci.), 40 (2006) 341-352.

2. W.Aloyce, D.Kuznetsov and L.S.Luboobi, A mathematical model for the mlnd dynamics and sensitivity analysis in a maize population, Asian Journal of Mathematics and Applications, 201(2017) 1-19.

3. T.L.Bucheyeki, Characterization and genetic analysis of maize germplasm for resistance to northern corn leaf blight disease in Tanzania.PhD thesis, University of KwaZulu-Natal, Pietermaritzburg, 2012 (2012) 1-198.

4. F.Chuma, G.G.Mwanga and D.Kajunguri, Modeling the role of wild birds and environment in the dynamics of newcastle disease in village chicken,Asian Journal of Mathematics and Applications, 2018 (2018) 1-23.

5. O.C.Collins and K.J.Duffy, Optimal control of maize foliar diseases using the plants population dynamics,ActaAgriculturaeScandinavica, 66(1) (2016) 20-26.

6. L.Contreras-Medina, I.Torres-.Pacheco, R.Guevara-Gonz'alez, R.Romero-Troncoso, T.Terol-Villalobos andR.Osornio-.Rios, Mathematical modeling tendencies in plant pathology,African Journal of Biotechnology, 8(25) (2009) 1-11.

7. N.C.Grassly and C.Fraser, Seasonal infectious disease epidemiology, Proceedings of the Royal Society of London B: Biological Sciences, 273(2006) 2541-2550. 
Fred Kapange, Jacob Ismail Irunde and Dmitry Kuznetsov

8. N.Imanbaevand B.Kalimbetov, A problem on eigenvalues of differential operator of the third order with non-local boundary value conditions, Journal of Mathematics and Informatics, 2018 (2018) 1- 6.

9. Y.Li and G.Ma, Evolutionary game analysis on the strategy selection of sharing bicycle enterprises and users, Journal of Mathematics and Informatics, Ix (2018) 3544.

10. V.Manstretta and V.Rossi, Effects of temperature and moisture on development of fusarium graminearumperithecia in maize stalk residues,Applied and Environmental Microbiology, 82(1) (2016) 184-191.

11. S.C.Mpeshe, L.S.Luboobi and Y.Nkansah-Gyekye, Modeling the impact of climate change on the dynamics of rift valley fever,Computational and Mathematical Methods in Medicine, 2014 (2014) 1-13.

12. C.Ngalya and D.Kuznetsov, Modelling the impact of bemisiatabaciin dynamics of tomato yellow leaf curl virus,Asian Journal of Mathematics and Applications, 2017 (2017) 1-19.

13. R.C.Ngeleja, L.S.Luboobi and Y.Nkansah-Gyekye, The effect of seasonal weather variation on the dynamics of the plague disease,International Journal of Mathematics and Mathematical Sciences, 2017 (2017) 1-26.

14. M.Nwanosike, R.Mabagala and P.Kusolwa, Disease intensity and distribution of Exserohilum turcicum incitant of northern leaf blight of maize in Tanzania,International Journal of Pure \& Applied Bioscience, 3(5) (2015) 1-13.

15. M.Nwanosike, R.Mabagala and P.Kusolwa, Effect of northern leaf blight (Exserohilum turcicum) severity on yield of maize (zea mays 1.) in Morogoro, Tanzania,International Journal of Science and Research, 4(9) (2015) 465-474.

16. O.Pechanova and T.Pechan, Maize-pathogen interactions: an ongoing Combat from a proteomics perspective,International Journal of Molecular Sciences, 16(12) (2015) $28429-28448$.

17. V.Rossi, E.Pattori and R.Bugiani, Sources and seasonal dynamics of inoculum for brown spot disease of pear, European Journal of Plant Pathology, 121(2) (2008) 147-159.

18. R.Singh and R.Srivastava, Nothern corn leaf blight- an important disease of maize: An extension fact sheet,Indian Research Journal of Extension Education,2(2) (2011) 339-241.

19. P.Van denDriessche and J.Watmough, Reproduction numbers and sub-threshold endemic equilibria for compartmental models of disease transmission,Mathematical Biosciences, 180(1-2) (2002) 29-48.

20. S.Wathaneeyawech., P.Sirithunya andP.Smitamana, Study of the host range of Northern corn leaf blight disease and effect of Exserohilum turcicum toxin on sweet corn,J. Agric. Technol, 11 (2015) 953-963.

21. K.Wise and D.Mueller, Are fungicides no longer just for fungi? Ananalysis of foliar fungicide use in corn. APSnet Features, 1-5, 2011.

22. S.Zhang. Application of fuzzy comprehensive evaluation inenvironmental quality assessment, Journal of Mathematics and Informatics, 13 (2018) 55-63. 